\title{
EM BUSCA DE UM PADRÃO DE CIDADANIA MUNDIAL
}

LEONARDO AVRITZER

O processo de globalização que se acentuou na década de 90 coloca uma série de questões para a teoria social contemporânea. Por um lado, os clássicos da teoria social abordaram a modernidade a partir do interior de tradições culturais disponíveis nos Estados nacionais. Assim, se autores como Karl Marx e Max Weber de alguma forma anteciparam algumas características do processo de globalização ou de mundialização em algumas das suas obras, eles sempre o fizeram reconhecendo a natureza eminentemente nacional das estruturas sociais analisadas, a saber o mercado e o Estado moderno. Por outro lado, os autores que, na modernidade tardia, passaram a operar com o conceito de globalização - em especial Giddens, Habermas e Boaventura de Souza Santos - têm tomado como ponto de partida para as suas teorias uma concepção geral da modernidade que, como procuraremos mostrar mais à frente, ainda esta marcadas pela prioridade do desenvolvimento de sociedades nacionais. Ou seja, categorias analíticas como as de esfera pública, diferenciação entre sistema e mundo da vida, distanciamento espaço-temporal, dualidade da estrutura, tensão entre regulação e emancipação expressam características de uma primeira modernidade, características essas intrinsecamente ligadas às culturas nacionais. Essa categorias tornam-se problemáticas ao serem estendidas para um nível maior de abstração no nível global ou mundial, e isso tem provocado mudanças nas teorias desses autores.

A questão acima torna-se ainda mais relevante quando analisamos o fenômeno da cidadania. A cidadania foi vista pelos clássicos das ciências sociais, em especial Karl Marx e Max Weber, como uma categoria relacionada às formas de vida concretas dos indivíduos-produtores e das comunidades. Nesse sentido, o marco analítico no interior do qual os clás- 
sicos das ciências sociais estruturaram a sua análise foi um marco de tensão entre formas de abstração identificadas com o surgimento do mercado e do Estado e formas concretas relacionadas às experiências do trabalho e às formas de solidariedade éticas de comunidades específicas. $\mathrm{O}$ recente processo de globalização, ao estender para fora do marco do Estado nacional os processos produtivos, as formas de acesso à comunicação, os movimentos de indivíduos e de mercadorias, ${ }^{1}$ coloca um problema para esses marcos analíticos: por um lado, ele coloca em crise, ainda que não dissolva, categorias concretas, tais como trabalho concreto, interação facea-face e comunidade, entre outros. Por outro, ele implica em uma extensão da forma de operação de categorias abstratas, especialmente, aquelas baseadas no mercado e no dinheiro. Como localizar o estatuto teórico do conceito de cidadania nessas condições?

O problema acima delimitado representa um problema não apenas para as teorias da cidadania baseadas em Marx e em Weber mas também para as teorias mais recentes propostas por três autores: Authory Giddens, Jürgen Habermas e Boaventura de Souza Santos. As categorias por eles apresentadas - o conceito de distanciamento espaço-temporal, a diferenciação entre sistema e mundo da vida e a tensão entre regulação e emancipação - todas elas buscam uma ancoragem em formas locais e concretas, no caso de Giddens (do primeiro Giddens) na comunidade política nacional, no caso de Habermas no mundo da vida enquanto produto de uma cultura nacional e local, e no caso de Boaventura de na recuperação de elementos dos conceitos de comunidade e de racionalidade estético-expressiva. $\mathrm{O}$ objetivo desse artigo é mostrar como todos os três autores tem enfrentado problemas heurísticos para estender as suas categorias pensadas no marco

1 Vale a pena, no entanto, dar uma dimensão mais precisa ao processo de mundialização ou globalização das relações econômicas, políticas e culturais. Hirst e Thompson relativizaram alguns dados, em especial no campo da economia, que põem em questão a amplitude do processo de internacionalização. Eles mostram, por exemplo, que ainda existe uma correspondência significativa entre poupança doméstica e investimento, ou que a maior parte das empresas transnacionais ainda dependem do consumo em algum tipo de Estado nacional. Ambos os dados relativizariam a extensão do processo de internacionalização da economia. Os autores também tentam relativizar historicamente o impacto do fluxo de mercadorias e especialmente do fluxo de indivíduos comparando-o com o existente no fim do século XIX. (Hirst e Thompson,1995). Alguns argumentos dos autores, no entanto, parecem muito unilaterias como, por exemplo, a concentração da análise do fluxo de indivíduos na imigração sem considerar que mais de 7 milhões de pessoas cruzam diariamente fronteiras no mundo atual ou que a produção de mercadorias simultanea em diversos países constitui de fato uma novidade no recente processo de globalização. 
de tradições culturais nacionais para uma dimensão transnacional. O nosso segundo objetivo será o de mostrar como construir em uma sociedade pósnacional as categorias concretas de uma cidadania mundial.

\section{MODERNIDADE, DIFERENCIAÇÃO E ABSTRATO/CONCRETO}

Desde o seu período clássico a modernidade está relacionada a um processo de tensão entre o concreto e o abstrato, tensão essa tratada por todas as teorias sociais contemporâneas. ${ }^{2}$ Essa tensão está ligada ao fato de que o processo de passagem de uma sociedade comunitária ou tradicional para sociedades modernas envolveu o surgimento de estruturas sociais com níveis maiores de abstração, tanto no campo da política quanto no campo da economia. Karl Marx talvez tenha sido o primeiro autor ${ }^{3}$ a utilizar categorias sociológicas para analisar esse processo. Ao analisar a forma mercadoria Marx observou que ela estabelecia uma dinâmica entre trabalho abstrato e trabalho concreto. "O corpo da mercadoria, o qual serve como equivalente, sempre aparece como incorporação de trabalho humano abstrato e, ao mesmo tempo, constitui o produto de alguma forma específica e útil de trabalho concreto"(Marx,1976,I:150). Para Marx a mercadoria, e consequentemente o mercado, estabelecia uma tensão entre abstrato e concreto, na medida em que reduzia uma atividade humana concreta, o trabalho, a um processo de abstração, processo esse necessário para tornar equivalentes diferentes tipos de trabalho. Assim, na origem da estrutura mercado encontra-se um processo de abstração, que na perspectiva marxiana estaria relacionado unicamente ao processo de dominação dos indivíduos produtores e não à sua emancipação.

É possível encontrar em Max Weber uma análise similar do processo de abstração da relações humanas. Na sua tipologia da direção

\footnotetext{
2 Vide a esse respeito, Domingues, 2000. Nesse artigo, o autor mostra como Lukacs recuperou o conceito associando as tradições marxiana e weberiana.

3 O conceito de abstração pensado a partir de uma formulação filosófica, tal como outros conceitos trabalhados por Marx, foi introduzido por Hegel.Em sua "Filosofia do Direito", assim como nas suas outras obras, Hegel sempre parte do abstrato que, do ponto de vista metodológico, siginifica o imediato, o que não possui nenhuma determinação. (Hegel,1952:35). Está em Hegel, portanto, a idéia de que tanto o abstrato, assim como o universal, são categorias externas ao indivíduo concreto. A tradução sociológica feita por Marx do conceito hegeliano transforma a abstração em formas externas impostas ao indivíduo concreto por um processo sistêmico que lhe é externo, no caso, a lógica auto-referenciada do capital. Tal constatação sociológica vai posteriormente gerar a idéia de reificação como externalidade.
} 
das rejeições religiosas do mundo Weber observa a presença de um sistema concreto de obrigações entre os indivíduos nas diferentes comunidades. Segundo Weber as comunidades tradicionais se estruturam a partir da dualidade entre membros internos e externos ao grupo principal. Os indivíduos desse primeiro grupo estavam subordinados a um tipo de moralidade interna: "Os ricos e os nobres eram obrigados a emprestar recursos livre de juros e a estender a sua hospitalidade e apoio. Os homens eram obrigados a prestar serviços aos seus vizinhos se requisitados"(Weber,1946:329). Com o surgimento da moderna economia de mercado instaura-se uma tensão entre uma ética concreta e um princípio abstrato de organização das relações econômicas: "Uma economia racional consiste em uma organização funcional orientada por preços monetários que se formou a partir dos interesses conflitantes entre os indivíduos no mercado. $\mathrm{O}$ cálculo não existe sem a possibilidade de estimar monetariamente os preços e, portanto, sem o conflito no mercado. $O$ dinheiro é o elemento mais abstrato e impessoal que existe na vida humana. Quanto mais o mundo da moderna economia de mercado segue a suas leis imanentes, menos ele se torna acessivel a qualquer ética de fraternidade". (Weber,1946:331; grifo meu).

Desse modo, tanto para Marx quanto para Weber existe uma tensão própria à formação das sociedades modernas, introduzida pelo processo crescente de abstração. Para Marx ela consiste no processo de abstração do trabalho de modo a torná-lo equivalente, e para Weber está ligado ao dinheiro e à forma como ele permite a abstração das relações concretas entre os indivíduos. Em ambos os casos essa tensão é vista como resultado dos processos modernos de racionalização, que, para Marx podiam ser deduzidos como um todo do surgimento e desenvolvimento de uma economia de mercado, enquanto para Weber estavam ligados a um processo inexorável de racionalização, que envolvia perda do controle do indivíduo sobre os processos de decisão administrativa, econômica, militar e científica (Weber, 1978, II). Em ambos os casos, identificavam a reconstrução de algum grau de liberdade para o indivíduo moderno com o processo de reconstrução de estruturas concretas na modernidade. Na "Crítica da Filosofia do Direito de Hegel" Marx encara o Estado moderno como uma abstração, ao afirmar que o Estado certamente é abstrato, mas que "a abstração é a do estado político tal como Hegel o apresentou ... Esse ponto de vista não pode ser considerado concreto quando o seu objeto é abstrato. Esse ponto de vista através do qual a sociedade civil é imersa pelas suas ações políticas é necessariamente uma conseqüência do fato da comunidade, a entidade comum, na qual o indivíduo vive, a sociedade civil, estar 
separada do Estado. Em outras palavras: o Estado político constitui uma abstração da sociedade civil." (Marx,1975:145). No entanto, o que Marx chama de razão essencial é dado pelo "carácter específico" do objeto que ele considerava existir no campo da sociedade civil (ibid, 181).

A passagem acima oferece um bom exemplo de como Marx encara a relação entre o abstrato e o concreto. Para ele o concreto é a comunidade, a forma real de vida econômica estabelecida pelos indivíduos produtores, ao passo que o abstrato são as categorias impostas pelo Estado e pelo direito abstrato e, segundo o Marx maduro, pela lógica do capital. A emancipação dos indivíduos na modernidade teria de estar de alguma maneira vinculada à recuperação da dimensão concreta da sociabilidade. Nesse sentido, Marx, ao pensar o concreto em escritos como a "Crítica do programa de Gotha" irá atacar justamente as estruturas de abstração do trabalho e, em especial, as estruturas do direito que permitiriam a abstração da condição humana.

A abordagem da relação entre concreto e abstrato feita por Weber é ligeiramente diferente da de Marx e, no entanto, aponta em uma direção semelhante. Como vimos acima, Weber percebe nos seus escritos sobre a religião uma tensão entre a forma concreta de vida em uma comunidade e o processo crescente de abstração imposto tanto pela economia de mercado quanto pelo direito abstrato. O direito moderno produz conflito devido à necessidade de gerar uma "construção jurídica dos fatos da vida com o intuito de colocá-los em sintonia com as proposições abstratas do direito"(Weber,1978,II:885). É possível perceber porque o problema weberiano é ligeiramente diferente do marxiano: para Weber o abstrato, ao invés de se constituir em uma estrutura de dominação do concreto, apenas não coincidiria com o concreto no caso do direito. Já no campo da economia a tensão entre abstrato e concreto implicaria um nível mais elevado de tensão: "A atividade econômica racional sempre trás consigo a despersonalização e é impossível controlar o universo de atividades racionais instrumentais mediante apelos à caridade de indivíduos particulares" (Weber,1978,I:585). Desse modo, Weber, diferentemente de Marx, entende que o processo crescente de abstração pode trazer ganhos em alguns campos da vida social, especialmente no campo do direito. No entanto, ele vê uma tensão insolúvel entre as formas de abstração introduzidas pela economia e a necessidade de uma posição de ação concreta em relação aos indivíduos e as comunidades desfavorecidas. Essa tensão, para a qual ele não aponta uma solução, derivaria da própria da contradição entre o abstrato e o concreto. 
É possível, portanto, perceber que tanto em Marx quanto em Weber a tensão própria a primeira modernidade é a que se estrutura entre as formas concretas de solidariedade (Marx) e caridade (Weber) próprias às relações concretas, relações essas que ambos os autores percebem estarem sendo substituídas por formas abstratas de relação nos campos da economia, do Estado e do direito. Ambos os autores percebem essa contradição como resultado de um processo de diferenciação social que para Marx seria reversível e, para Weber, inevitável ainda que altamente problemático. $\mathrm{O}$ que irá diferenciar os autores da primeira modernidade - Marx e Weber dos autores da segunda modernidade - Habermas, Giddens e Boaventura será a aceitação da inevitabilidade da diferenciação social autores que irão pensar a modernidade tardia. Na próxima seção desse trabalho procurarei mostrar de que modo a tensão entre abstrato e concreto é retrabalhada por esses autores e onde eles localizariam os potenciais de emancipação na modernidade tardia.

\section{MODERNIDADE TARDIA, DIFERENCIAÇÃO E CIDADANIA}

Nos anos finais da século XX três autores voltaram a tratar do problema da modernidade na sua relação entre abstrato e concreto, buscando determinar um padrão de cidadania a partir dessa diferenciação. São eles: Anthony Giddens, Jürgen Habermas e Boaventura de Souza Santos. Nessa seção desse artigo irei mostrar como a definição de cidadania na teoria de cada um desses autores está intimamente ligada a forma como eles irão propor uma teoria da diferenciação social e, a partir dela, como eles irão resgatar uma dimensão concreta de cidadania nas sociedades contemporâneas.

Anthony Giddens, desde o início da sua obra, procurou trabalhar com o conceito de modernidade aceitando a inevitabilidade da diferenciação social. Já na sua "crítica contemporânea ao materialismo histórico" Giddens vai retrabalhar o problema da diferenciação social e da sua relação com a perda do controle dos indivíduos sobre as suas relações sociais a partir do conceito que irá se tornar central na sua obra, o conceito de distanciamento espaço-temporal. Segundo Giddens, "a estruturação de qualquer sistema social, grande ou pequeno, ocorre no tempo e no espaço e, ao mesmo tempo, coloca o tempo e o espaço entre parênteses. A combinação entre a presença e ausência é inerente à natureza constitutiva dos sistemas sociais: cada sociedade participa em alguma forma de dissolução de constrangimentos espaço-temporais." (Giddens,1981:91). Ao lançar o conceito 
de distanciamento espaço-temporal Giddens irá fornecer à sua obra uma embocadura imediatamente relacionada aos processos de abstração próprios da economia de mercado e do Estado moderno. Para ele, toda forma de relação social passa por um processo de estocagem (storage) de dois tipos de recursos: os alocativos e os autoritativos. O processo de distanciamento espaço-temporal envolve essa dimensão ao permitir, via desenvolvimento do mercado, a estocagem de recursos econômicos no tempo e no espaço. Ao mesmo tempo, toda sociedade, através de uma forma diferente de Estado, permite um processo de estocagem de recursos autoritativos no tempo e no espaço. Assim, o processo de estocagem de recursos alocativos ou autoritativos no tempo e no espaço permite desencaixar as relações econômicas e politicas de um local determinado, tornando-as abstratas. Para Giddens tanto o mercado quanto o Estado se tornam formas de controle da apropriação pelos indivíduos da economia e da política, controle esse exercido através da abstração das relações sociais no espaço e no tempo.

É possível perceber, no primeiro Giddens, a influência do arcabouço teórico marxiano na forma como ele descreve o processo de distanciamento espaço-temporal como um processo de perda do controle dos indivíduos sobre a sua vida. Para Giddens "a mercantilização do tempo significa a inserção do tempo na dupla existência que constitui o predicado de qualquer mercadoria. O tempo como tempo vivido, como a substância da experiência vivida, da durée do ser, passa a estar acompanhado de uma dimensão independente, o tempo puro na sua duração informe (formless). Com a expansão do capitalismo isso é o que o tempo parece ter- se tornado, assim como o dinheiro se tornou o padrão universal de todas as coisas. O tempo como pura duração, desconectado da materialidade da experiência, passa a ser percebido, em oposição direta ao estado real das coisas, como tempo real objetivo...'(Giddens,1981:131). Ou seja, o primeiro Giddens, na sua análise do processo de distanciamento espaço-temporal, chega, da mesma forma que Marx e Weber, ao problema da relação entre concreto e abstrato, relação essa estruturada a partir da tensão entre o tempo enquanto experiência vivida e o tempo enquanto categoria abstrata. Giddens irá desenvolver uma categoria para analisar essa tensão, a categoria de dualidade da estrutura.

Na sua obra sobre a "constituição da sociedade" Giddens irá mostrar que o processo de distanciamento espaço-temporal não constitui uma estrutura fixa no interior da qual os indivíduos agem. Pelo contrário, o autor irá defender a idéia da dualidade da estrutura, isto é, o fato de as 
estruturas não representarem apenas constrangimentos estabelecidos pelo processo de distanciamento espaço-temporal mas também possibilidades abertas por esse mesmo processo. Giddens irá identificar essas possibilidades com a contextualidade da interação. Segundo o autor a contextualidade envolveria "os limites espaço-temporais (que em geral possuem marcadores simbólicos ou físicos) em torno das faixas interativas; a co-presença de atores tornando possível a visibilidade das expressões faciais, dos gestos corporais e das formas lingüísticas e dos outros meios de comunicação; e a percepção e uso desses fenômenos de forma reflexiva para influenciar ou controlar o fluxo das interações" (Giddens, 1984:282).

Não é difícil perceber que tanto o primeiro Giddens da "crítica contemporânea ao materialismo histórico" quanto o Giddens intermediário da "constituição da sociedade" trabalham na interseção entre um processo de diferenciação e um processo interativo de reflexão e resistência às duas formas principais de distanciamento espaço-temporal na modernidade: a estocagem de recursos alocativos e autoritativos no interior das instituições mercado e Estado. Nesse sentido, é a recuperação das categorias interativas que Giddens irá identificar com o concreto da experiência temporal dos atores sociais o que irá possibilitar um balanço entre as dimensões sistêmicas e interativas. A questão da cidadania vai estar em Giddens, como esteve em Marx e em Weber, vinculada a essa dimensão: para ele, a cidadania estará ligada às lutas concretas ocorridas no interior do Estado nacional e irá pressupor uma associação singular entre territorialidade e homogeneidade cultural: "Com o advir do Estado nacional, os estados passam a ter uma unidade territorial e administrativa que eles não possuíam antes. A extensão da comunicação não poderá ocorrer sem um envolvimento 'conceitual' de toda a comunidade enquanto uma cidadania com conhecimento de causa (knowledgeable citizenry). O partilhamento de uma linguagem comum e de uma historicidade simbólica comum são as formas mais completas de alcançar [essa unidade]."(Giddens, 1987:219).

A forma como Giddens estrutura a relação entre o processo de distanciamento espaço-temporal e a emergência da cidadania produz uma tensão imanente extremamente grave para a sua teoria. Por um lado, o primeiro Giddens busca identificar as potencialidades emancipatórias da modernidade através do que ele denomina dualidade da estrutura, apontando na direção da interação face-a-face, categoria essa que implica em uma contextualidade e uma cultura específicas. Por outro lado, a forma como o processo de distanciamento espaço-temporal adquire, desde o primeiro Giddens, centralidade na modernidade irá obrigá-lo, ao tratar do processo 
de globalização, a romper com a categoria do concreto e apostar nos limites emancipatórios das formas de abstração. Tratarei desse ponto na próxima seção deste artigo. Antes porém, demonstrarei de que maneira dois outros autores - Habermas e Boaventura - irão tratar da relação entre abstrato e concreto na modernidade tardia.

Jürgen Habermas pode ser considerado entre os clássicos da teoria social contemporânea aquele que mais preservou o arcabouço original proposto por Marx e Weber. Habermas discute a diferenciação social pensando a relação entre dois subsistemas, o do mercado e o do Estado, e uma categoria que ele reconstrói com base na fenomenologia alemã, a categoria de "mundo da vida". Para ele a modernidade é o processo evolutivo de diferenciação entre sistema e mundo da vida, processo através do qual o sistema é diferenciado de mundo da vida e o subsistema mercado se diferencia do subsistema Estado. Para Habermas a modernidade, do ponto de vista sistêmico, implica emergência de novas formas de complexidade:

"O desacoplamento entre sistema e mundo da vida se dá de tal forma que, o mundo da vida, a princípio escassamente diferenciado do sistema social... torna-se um sub-sistema entre outros. No decorrer desse processo, os mecanismos sistêmicos se tornam mais e mais separados das estruturas sociais através das quais a integração social ocorre... As sociedades modernas atingem um nível de diferenciação sistêmica que propicia que organizações sejam conectadas umas com as outras através de meios não lingüísticos de comunicação; tais mecanismos sistêmicos - por exemplo, o dinheiro, estabelecem formas de relação social largamente desconectados de normas e valores..."(Habermas, 1984,II:154).

A passagem acima nos permite localizar a teoria habermasiana tanto em relação a Marx e a Weber quanto em relação à obra do primeiro Giddens. Em relação tanto à obra de Marx quanto a de Weber, o objetivo de Habermas é preservar o diagnóstico da modernidade feito pelos dois autores e, ao mesmo tempo, relativizá-lo. Habermas transforma os diagnósticos marxiano e weberiano da reificação e da perda do sentido, que os dois autores conceberam enquanto fenômenos genéricos provocados pela modernidade, em consequiência de processos característicos de cada um dos subsistemas - no caso, a economia de mercado e o Estado moderno em patologias provocadas não pelos subsistemas e sim pela sua expansão. Desse modo, Habermas reduz a reificação ao que ele denomina de monetarização e reduz o fenômeno da perda do sentido àquilo que ele denomina burocratização. O seu objetivo é mostrar que os processos de abstração próprios à modernidade não tem per se as consequiências patológicas 
descritas tanto por Marx quanto por Weber: "A transformação das atividades concretas de trabalho em força de trabalho abstrata que pode ser vendida como mercadoria serviu para Marx como modelo do processo de abstração real. Tal processo é desencadeado cada vez que o mundo da vida, nas suas trocas com o sistema econômico e administrativo tem que se adaptar aos meio de controle sistêmicos...Nós veremos que [ o processo descrito acima L.A.] tem uma correspondência na relação entre o Estado de bem estar social e seus clientes. Esse constitui, na verdade, o caso modelo de colonização do mundo da vida que está por detrás dos fenômenos de reificação nas sociedades capitalistas avançadas... Nesse caso, os elementos de uma forma privada de vida e de tradições político-culturais são separados das suas formas simbólicas de vida através da redefinição monetária de objetivos...e através da burocratização de decisões, obrigações e direitos" (Habermas, 1984,II:322). É possível perceber que na própria descrição do fenômeno da colonização a questão da relação entre abstrato e concreto aparece em uma tentativa de redimensionar os processos descritos tanto por Marx quanto por Weber. Por outro lado, diferentemente do primeiro Giddens, que tentou mostrar que a redefinição ampla do processo de abstração ou distanciamento espaço-temporal poderia ser feita interativamente, Habermas irá adotar um programa mais limitado e defensivo. De acordo com esse programa a colonização do mundo da vida seria decorrência não da existência dos meios dinheiro e poder, mas ocorreria apenas quando esses meios penetram em estruturas simbolicamente mediadas que necessitam da linguagem.

A preocupação habermasiana será a reconstrução dessas estruturas, que ele irá identificar com os potenciais culturais do mundo da vida, pensado nos termos das culturas construídas no interior do Estado nacional. Para Habermas os potenciais emancipatórios irão manifestar-se através da defesa e da restauração de formas de vida em perigo, formas essas relacionadas "às gramáticas das formas de vida", uma dimensão eminentemente concreta. Habermas irá atribuir às ações políticas na esfera pública a criação de fluxos democráticos de controle do sub-sistema Estado (Habermas,1995) e a defesa dessas gramáticas de vida postas em perigo. O problema que irá se colocar para a teoria habermasiana com o avanço do processo de globalização será o seguinte: qual será a categoria que irá no plano internacional se contrapor a um acentuamento do processo de abstração criado pelo surgimento de um mercado internacional ou da expansão do Estado através da constituição de uma unidade política supraterritorial? A sobrevivência de uma tensão entre abstrato e concreto 
ou entre subsistemas e mundo da vida será possível somente se for possível encontrar no plano internacional de um mundo globalizado uma categoria concreta que permita a reconstrução da categoria de cidadania em um nível internacional. Portanto, tal como a teoria do distanciamento espaçotemporal, a teoria da separação entre sistema e mundo da vida enfrenta problemas para se tornar uma teoria de uma cidadania mundializada. Antes de mostrar como a teoria habermasiana irá responder a esse problema pretendo mostrar como uma terceira tradição de teoria crítica, aquela proposta por Boaventura de Souza Santos, abordou a questão da relação entre o abstrato e o concreto na modernidade tardia. ${ }^{4}$

Da mesma forma que Giddens e Habermas, Boaventura de Sousa Santos entende a modernidade como um processo de diferenciação. Para ele, dois tipos distintos de diferenciação ocorreram na modernidade: a diferenciação entre Estado, mercado e comunidade, e a diferenciação entre três tipos de racionalidade: a cognitivo-instrumental, a prático-moral e a estético-expressiva. ${ }^{5}$ Para Boaventura, o primeiro eixo da diferenciação estaria ligada ao eixo da regulação e seria baseada na idéia de obrigação, enquanto o segundo eixo estaria ligado à idéia de emancipação: "O princípio do Estado consiste na obrigação política vertical entre cidadãos e Estado. O princípio do mercado consiste na obrigação política horizontal, individualista e antagônica entre os parceiros de mercado. O princípio da comunidade consiste na obrigação política horizontal solidária entre os membros da comunidade e entre associações" (Santos,2000:50).

\footnotetext{
${ }^{4} \mathrm{Na}$ verdade Boaventura de Sousa Santos trabalha com o conceito de pós-modernidade. Na "Crítica da Razão Indolente", o autor diferencia a modernidade da pós-modernidade através da emergência, no segundo caso, de um conhecimento sempre contextualizado e sempre atento às condições que o tornam possível. No entanto, o próprio autor reconhece que a maior parte do pensamento pós-moderno atual é celebratório e que a grande oposição epistemológica do fim do século XX termina sendo a oposição entre a modernidade e a pós-modernidade. (Santos,2000:36-37). Por todos esses motivos prefiro trabalhar o pensamento do autor a partir da categoria de modernidade tardia.

$5 \mathrm{O}$ entendimento da modernidade como um processo de diferenciação de três esferas axiológicas remete a Max Weber, ainda que Weber de saída já tenha colocado em questão os potenciais emancipatórios dessas esferas e trabalhado com a idéia de fragmentação. Em "A ciência como vocação" Weber irá tratar da oposição entre a ciência, o direito e a moral pretendendo mostrar que cada uma dessas esferas possui um critério próprio de racionalidade em oposição ao das outras esferas. Para Weber, "alguma coisa pode ser verdadeira, ainda que não seja sagrada, bela e nem boa...esses casos [de conflito entre as diferentes ordens valorativas L.A.] são os mais elementares na luta que os deuses das várias ordens e valores se estão empenhando". (Weber,1946:148). O argumento de Weber é que apenas a ciência se preserva na luta entre as várias esferas de valores. Boaventura retoma o diagnóstico weberiano atribuindo à ciência um caráter de dominação do senso comum. Para uma crítica a posição de Weber sobre o diagnóstico do politeísmo das ordens de valor, vide Avritzer,1996.
} 
Na forma como ele concebe a questão da diferenciação e da obrigação política encontramos um grande semelhança entre Boaventura, Giddens e Habermas no sentido de entender a necessidade e a permanência dos processos de diferenciação. A originalidade da concepção de modernidade proposta por Boaventura irá se manifestar na forma como ele transfere o problema da abstração e das estruturas da dominação do campo do mercado e do Estado para o campo da ciência e do direito. Para Boaventura, não é no eixo Estado, mercado e comunidade onde os problemas da modernidade irão se manifestar mas sim no eixo ciência e direito. Estas duas categorias, que originalmente estavam destinadas no projeto original da modernidade a se constituírem como categorias emancipatórias $^{6}$, tornaram-se eixos a partir dos quais a regulação se processa. Tanto a ciência quanto o direito foram se tornando eixos de regulação na medida em que a modernidade se desenvolvia: "Promovidos pela rápida conversão da ciência em força produtiva, os critérios científicos de eficiência e eficácia logo se tornaram hegemônicos, ao ponto de colonizarem gradualmente os critérios racionais das outras lógicas emancipatórias." (Santos,2000:51). Desse modo, o que passamos a ter na modernidade tardia, foi a absorção do pilar da emancipação pelo pilar da regulação; mercado, ciência e direito se associam em um projeto regulativo hegemônico capaz de anular potenciais emancipatórios.

No entanto, para Boaventura, da mesma forma que para Habermas e para Giddens, o pólo da emancipação não se esgotou. Ele continuaria presente em duas categorias, uma delas presente no pólo da regulação e a outra presente no pólo da emancipação: trata-se das categorias comunidade e racionalidade estético-expressiva. A comunidade, apesar de localizada por ele inicialmente no pólo da regulação em virtude das formas de obrigação entre os indivíduos por ela gerada, retêm, ao longo da modernidade potenciais de emancipação: "Porque é uma representação aberta e incompleta, a comunidade é ela própria dificilmente representável... e os seus elementos constitutivos são também eles abertos e inacabados...Tem, contudo, uma característica comum: todos resistiram à diferenciação técnico-científica através das quais a racionalidade cognitivoinstrumental da ciência moderna colonizou os outros princípios da regu-

\footnotetext{
6 Certamente a ciência moderna foi vista, inicialmente, em especial, pela tradição marxiana como a categoria produtora da emancipação. Para Marx, o ato de reflexão próprioà atividade produtiva era ao mesmo tempo um ato de transformação e domínio da natureza. É nesse ponto que se funda boa parte do determinismo econômico e da teleologia própria ao pensamento marxiano. Vide Avritzer,1996.
} 
lação: o mercado e o estado."(Santos,2000:75). Ou seja, o que Boaventura procura apontar na modernidade é o processo através do qual Estado e mercado são subordinados à lógica da ciência, lógica essa que é de abstração do conteúdo e de criação de uma lógica da eficácia e da instrumentalização. A comunidade, por ter sido entre os três pilares da regulação o menos susceptível à regulação instrumental é o que preserva algumas categorias emancipatórias - em especial as idéias de solidariedade e de participação. Seria, no entanto, o caso de perguntar se, de fato, ele está correto ao identificar o pólo da comunidade junto ao da regulação, na medida em que ela apresenta, desde o início da modernidade, subcategorias emancipátorias, tais como a solidariedade e a participação, isso é, as categorias do concreto. ${ }^{7}$ A mim pareceria mais correto localizar a comunidade entre a regulação e a emancipação.

Há, ainda, uma segunda categoria emancipatória na modernidade apontada por Boaventura, a racionalidade estético-expressiva. Segundo ele, ao longo da modernidade, ao mesmo tempo em que as racionalidades prático-moral e cognitivo-instrumental tiveram suas características alteradas, a racionalidade estético-expressiva manteve algumas das suas características emancipatórias, entre elas, as noções de prazer, de autoria e de artefactualidade discursiva. Especialmente as duas últimas permitem o que Boaventura denomina reconstrução de um conhecimentoemancipação, isso é, um conhecimento local criado e disseminado através do discurso argumentativo (Santos,2000:95). Tal discurso envolveria a reconstrução de um senso-comum emancipatório que pudesse se opor à hegemonia da racionalidade cognitivo instrumental e, portanto, contribuir para a reconstrução do potencial emancipatório em seis espaços-tempos: no doméstico, no da produção, no do mercado, no da comunidade, no da cidadania e no espaço mundial.

Não é difícil perceber que a reconstrução da emancipação em Boaventura implica resgatar o concreto, que o autor identifica com um senso comum emancipatório. Diferentemente de Habermas e de Giddens, que identificam a cidadania com uma forma de reconstrução de dimensões interativas que resistem aos processos de abstração próprios à mo-

7 É possível identificar dois problemas na forma como Boaventura localiza o conceito de comunidade no eixo da regulação. $O$ primeiro deles é que a comunidade detêm uma série de elementos que ele irá identificar com o pólo da emancipação, por exemplo, a idéia da argumentação. Em segundo lugar, fica difícil basear na comunidade os potenciais emancipatórios da globalização, o que ira fazer com que ele trabalhe nos seus escritos sobre globalização mais com a idéia de cultura do que com a de comunidade. 
dernidade, Boaventura identifica a abstração a um tipo de racionalidade, a cognitivo instrumental, com sua capacidade de impor leis científicas abstratas em outros campos, em particular no campo do direito. Ao mesmo tempo procura resgatar na modernidade uma forma distinta de racionalidade, que ele irá identificar à racionalidade estético-expressiva, com duas das categorias por ela geradas: a de autoria e a de artefactualidade discursiva. Uma vez reconstruída uma racionalidade alternativa - um empreendimento que nos recorda o esforço habermasiano - Boaventura procura reconstruir dimensões do concreto, que ele irá identificar numa interatividade argumentativa, nas seis áreas já mencionadas acima. Ao fazê-lo ele irá conectar cada uma dessas seis áreas a uma dimensão concreta, a saber, a interatividade argumentativa, que se manifesta de forma particularmente aguda no direito moderno. Para Boaventura de Souza Santos o direito moderno pode ser definido como "um corpo de procedimentos regularizados e de padrões normativos considerados justificados em um dado grupo social, que contribui para a criação e prevenção de litígios e para a sua resolução através de um discurso argumentativo articulado com a ameaça de força. Dizem-se justificados os procedimentos e os padrões normativos com base nos quais se fundamentam pretensões contraditórias e se geram litígios capazes de serem resolvidos por terceiras partes"(Santos,2000:290).

Não é difícil perceber que o direito constitui a área da modernidade na qual a disputa entre abstrato e concreto estaria mais em evidência. Por um lado, diferente da ciência, que para Boaventura sucumbiu definitivamente à idéia de leis abstratas, o direito possui duas características que serão centrais para a sua reconstrução emancipatória: ele opera em campos sociais concretos que não são redutíveis às formas de abstração do direito moderno próprias ao Estado nacional. Esse último, ao unificar o direito em uma base territorial, impôs um certo processo de abstração ao processo de aplicação de normas. No entanto, não conseguiu subordinar as outras constelações de juridicidade. É no interior dessas constelações, que envolvem seis tipos de direito - o direito doméstico, o direito de produção, o direito de troca, o direito da comunidade, o direito territorial e o direito sistêmico - que irá ocorrer a tensão entre abstrato e concreto, motivada pelo fato de não coincidir a dinâmica de desenvolvimento do direito estatal com o senso comum e com as práticas em cada uma dessas seis áreas. Assim, por exemplo, no campo do direito doméstico haveria um lugar incerto para os direitos de consumo, assim como no campo do direito de produção haveria um lugar incerto para os direitos ligados ao trabalho, assim como no campo do direito territorial estatal haveria uma forma 
comum de sanção da cidadania que estaria em tensão com a emergência de novas direitos, como os direitos ambientais. Ou seja, apesar do grande mérito do direito estatal ser a capacidade de circular pelos diferentes espaços estruturais, esse mesmo direito teria uma insuficiência original, que seria a sua incapacidade de dar conta de formas concretas de desigualdade. "A igualdade da cidadania colide, assim, com a diferença da subjetividade, tanto mais que no marco da regulação liberal essa igualdade é profundamente seletiva e deixa intocadas diferenças, sobretudo as de propriedade, mas também as da raça e do sexo que mais tarde vão ser objetos centrais das lutas igualitárias."(Santos,1995:240).

Mais uma vez, percebemos que o ponto de chegada de Boaventura de Sousa Santos, tal como o de Giddens e de Habermas, é o concreto. As formas concretas de argumentação e a diferença nas seqüências lógicas de cada um dos seis campos não podem ser desprezadas pelas formas de abstração do direito territorial, que apenas foi capaz de criar uma forma restrita de cidadania. Para Boaventura a cidadania deveria estar ligada " à formas político-jurídicas que, ao contrário do direito geral e abstrato, incentivem a autonomia e combatam a dependência burocrática, personalizem e localizem as competências interpessoais e coletivas" (Santos,1995:264). A questão, no entanto, que se coloca para ele, assim como para Giddens e Habermas, é a seguinte: como ampliar os espaços argumentativos próprios das seis formas do direito quando o processo de globalização em curso implica aumento das abstrações ligadas ao direito territorial ou implica criação de uma abstração supraterritorial?

\section{GLOBALIZAÇÃO, CIDADANIA E CONCRETUDE}

Os diferentes autores discutidos até agora deram respostas radicalmente diferentes ao problema da ampliação da cidadania no interior do atual processo de globalização. Anthony Giddens foi, entre os três, o que mais profundamente reviu a sua teoria para adaptá-la ao processo de globalização em curso. Giddens tratou o processo de globalização com mais profundidade em "Além da esquerda e da direita". Nas páginas iniciais dessa obra, na própria definição do processo de globalização, podemos perceber que algo próximo de uma revolução copernicana no pensamento do autor está ocorrendo. Para Giddens "a globalização não é, nem mesmo primariamente, um processo econômico e nem deve ser ligada à emergência de um 'sistema mundial'. A globalização diz respeito à transformação 
do espaço e do tempo. Eu a defino como a ação à distância e relaciono a sua intensidade, nos anos recentes, à emergência de meios instantâneos de comunicação global e transporte de massas. A globalização diz respeito não apenas à criação de sistemas de larga escala mas também à transformação dos contextos locais e pessoais da experiência social." (Giddens, 1994:4-5).

Não é possível subestimar as conseqüências da definição de globalização feita por Giddens para posições por ele defendidas até aquele momento. Uma conseqüência principal pode ser apontada, a saber, o fato da definição da globalização como ação a distância no interior do processo de distanciamento espaço-temporal anular a possibilidade da dualidade da estrutura e da ação no contextos interativos. Giddens irá mostrar em "Além da direita e da esquerda" que o contexto da interação face-a-face defendida na "Constituição da sociedade" torna-se inviável na modernidade tardia. ${ }^{8}$ Para Giddens o componente central das sociedades na modernidade tardia não é mais algum elemento interativo ou coletivo e sim a figura do self conectado ao processo de formação da auto-identidade. A auto-identidade constitui o processo no qual "o self é entendido reflexivamente pela própria pessoa nos termos da sua biografia. A identidade, nesse caso, assume continuidade ao longo do tempo e do espaço: mas a autoidentidade é essa continuidade interpretada reflexivamente pelo agente."(Giddens, 1991:53).

Não é possível subestimar as mudanças que tal concepção traz em relação à obra do primeiro Giddens, a principal delas sendo uma radical reinterpretação da idéia de abstração. Em "Modernidade e auto-identidade" e em "As conseqüências da modernidade" o conceito de abstração vai ter jogar um papel completamente distinto daquele por ele desempenhado na obra do primeiro Giddens, passando a ocupar uma posição secundária em relação aos conceitos de desencaixe e reencaixe. Por desencaixe Giddens entende o processo de elevação e deslocamento (lifting out) das relações sociais dos contextos locais e sua rearticulação em uma outra

$8 \mathrm{O}$ autor que mais claramente defende essa perspectiva é John Thompson. Para Thompson nossa maneira de pensar "sobre a publicidade deriva do mundo antigo, das assembléias e praças públicas da Grécia antiga. Este é o modelo tradicional da publicidade de co-presença...Hoje devemos reconhecer que... o desenvolvimento dos meios de comunicação... criou novas formas de publicidade que não partilham as características do modelo tradicional. Essas novas formas de publicidade mediada tem, na sua maioria, um carácter não dialógico. Vide Thompson,1995:244. Para uma tentativa de integrar as formas de interação com a publicidade mediada, vide Avritzer,2000. 
dimensão espaço-temporal (Giddens,1991:18;Giddens,1990:21). Duas características do desencaixe e do reencaixe merecem ser destacadas: a primeira é que o desencaixe substituti o conceito de diferenciação ${ }^{9}$ e adquire uma conotação positiva. A segunda é que, se o desencaixe e o reencaixe envolvem processos sociais, eles, no entanto, são atividades do self e passam a estar muito menos ligados à idéia de cidadania do que a idéia de um self reflexivo. Ao mesmo tempo, muda na obra de Giddens a conotação do conceito de abstração, que passa a ter uma avaliação neutra e evolutiva, ligada à passagem das formas pessoais às formas impessoais de confiança: "A confiança nos sistemas abstratos fornece a segurança no dia a dia, mas pela sua própria natureza não pode fornecer a mutualidade ou a intimidade que as relações pessoais oferecem... No caso dos sistemas abstratos, por outro lado, a confiança supõe a crença em princípios impessoais... Indivíduos em pontos de contato ... estabelecem a conexão entre a confiança pessoal e a confiança sistêmica" (Giddens, 1990:114-115).

A solução dada por Giddens ao desenvolvimento do processo de globalização é claro: ele supõe que o processo de distanciamento espaçotemporal passa a ter uma dimensão fundamentalmente potencializadora para os indivíduos desencaixados que substituem a sua confiança nas estruturas concretas por confiança nas estruturas abstratas. Todos o problema do contexto reflexivo da interação é substituído pela reflexividade do self, reflexividade que expressa a própria confiança nos sistemas abstratos. A categoria de concreto ou mesmo a categoria de cidadania deixam de fazer sentido, na medida em que os indivíduos podem se reencaixar no mundo globalizado e na medida em que a categoria de reflexão encontra uma ancoragem individual. Giddens, com sua adesão acrítica ao processo de globalização, deixa de problematizar a desigualdade entre as formas de extensão espaço-temporal do mercado e as formas de reflexão acessíveis aos indivíduos. Ele também não consegue de maneira nenhuma mostrar com o self reflexivo pode gerar instituições internacionais mais democráticas ou defender formas multiculturais de cidadania. Ele não é capaz de fazê-lo porque não sobra nenhuma categoria coletiva e crítica na forma

\footnotetext{
${ }^{9}$ Dois conceitos são centrais na análise do desencaixe,o de fichas simbólicas e de sistema de peritos. O conceito de fichas simbólicas é uma reinterpretação da capacidade de abstração provocada pelo dinheiro, agora interpretada por Giddens apenas no seu papel potenciador do distanciamento espaço-temporal. O conceito de sistema de peritos é uma reinterpretação do conceito de burocracia em Weber estendido às diferentes áreas e pensado apenas a partir da potencialização do distanciamento espaço-temporal. Ambos vão implicar ruptura com o conceito de abstração como negatividade. Vide Giddens, 1990.
} 
como ele descreve o processo de globalização. Esse é o preço que a sua teoria paga por abandonar a distinção clássica entre concreto e abstrato proposta por Marx e por Weber.

Jürgen Habermas assume uma posição muito mais cuidadosa e reflexiva ao tratar do processo recente de globalização. Em "A constelação nacional e o futuro da democracia"Habermas reavalia a trajetória do Estado de bem estar social na modernidade para tentar analisar quais foram as modificações pelas quais esse último passou e quais são as possibilidades de ampliar o escopo da democracia frente ao processo recente de globalização. Para Habermas tanto a democracia quanto a cidadania na modernidade estiveram vinculados a algum processo de homogeinização cultural: "A autodeterminação democrática apenas pode ocorrer quando a população do Estado se converte em uma nação de cidadãos que tomam em suas próprias mãos o seu destino político. No entanto, a mobilização política dos 'súditos' exige, em primeiro lugar, a integração cultural de uma população heterogênea"(Habermas,2000:88). A afirmação tem um objetivo meramente constativo, o que não deixa de envolver problemas no momento de acentuação do processo de globalização, processo esse que Habermas entende de modo tanto infra-estrutural quanto cultural. Para ele, a globalização consiste no "crescente volume de tráfego, comunicação e intercâmbio além das fronteiras nacionais", um processo que assume diferentes dimensões: a extensão intercontinental da comunicação, a cultura e o turismo de massas. (Habermas,2000:90). Assim, por um lado, o processo de globalização implica a extensão dos processos sistêmicos além das fronteiras nacionais e, por outro lado, ele implica, também, a extensão de um pano de fundo cultural para além do espaço nacional. A questão política central para uma teoria da democracia é: como pensar a reconstrução da democracia, uma vez que a tradição do Estado nacional no interior da qual a democracia foi praticada nos últimos 200 anos se enfraquece?

Habermas irá discutir em que medida seria possível identificar potenciais culturais pós-nacionais que justificassem uma extensão da cidadania e da democracia para além do Estado nacional da mesma forma que, através dos mercados, a infra-estrutura de comunicação e de intercâmbio comercial foi internacionalizada. Para Habermas a história européia desde a mais tenra modernidade é uma história contraditória de aberturas e fechamentos, capaz tanto de produzir patologias sociais decorrentes do desenraizamento dos indivíduos das suas tradições quanto de provocar o fim de formas autoritárias de dependência e a geração de formas mais amplas de integração social.(Habermas,2000:130). Ou seja, a 
desaparição das ataduras decorrentes de um mundo da vida altamente integrado deixa o indivíduo ambivalente frente a um conjunto de opções possíveis. Portanto, a questão que se coloca para a democratização do processo corrente de globalização seria a localização de potenciais de produção cultural em nível pós-nacional capazes de ancorar uma extensão da democracia e da cidadania para além do Estado nacional. Por um lado, Habermas reconhece que houve uma ampliação do marco cultural da modernidade para além das culturas nacionais: indivíduos de diversas partes do mundo podem estabelecer uma comunicação diária entre si trocando mensagens pela Internet; já existem fatos políticos mundiais que podem constituir um pano de fundo para uma convivência política pós-nacional, o que possibilitaria apontar na direção de um novo concreto nas relações entre os indivíduos, que poderia vir a se constituir em um pano de fundo para uma experiência democrática e cidadã pós-nacional. Essa experiência trataria da tensão entre o concreto e o abstrato no nível internacional, ao tratar questões como: a flexibilização das atividades produtivas do trabalhador versus a desregulamentação do mercado de trabalho, a pluralização das formas de vida versus a fragmentação social, a representação política pós-nacional versus a perda da soberania das comunidades políticas. No entanto, para Habermas, o que falta no mundo pós-nacional ainda seria "um contexto de uma cultura política comum a que as diversas partes possam recorrer no que diz respeito às orientações de valor e às idéias de justiça e que poderiam tornar possível um entendimento além de um compromisso racional com respeito a fins" (Habermas,2000:142).

A posição habermasiana mostra os limites de um possível processo de globalização cultural baseado na idéia de uma extensão do marco de distinção entre sistema e mundo da vida. Por um lado, o autor reconhece que a possibilidade de manter a distinção entre abstrato e concreto e, portanto, distinguir os processos de extensão do mercado e da organização política para além do espaço nacional, tem de estar diretamente relacionada à criação de uma instância político-cultural internacionalizada formada pela própria extensão do processo de reflexão cultural para além do Estado nacional. Nesse sentido Habermas vai além de Giddens, pois não sucumbe à abstração do mercado e continua operando com uma categoria concreta, a interação face-a-face ou mediada entre os indivíduos capaz de produzir novas formas concretas de solidariedade. Por outro lado, o eurocentrismo que caracteriza boa parte das suas formulações (Santos, 2000), o impede de postular um processo amplo de diálogo entre as diferentes tradições culturais e preferir pensar a extensão de uma base cultural 
comum limitada à própria Europa (Costa,2001). É essa a resposta de Habermas à questão da globalização cultural: o reconhecimento de que "a solidariedade cívica, limitada até agora ao Estado-nação deve estender-se de tal maneira aos cidadãos da União que, por exemplo, os suecos e os portugueses se sintam mutuamente solidários." (Habermas,2000:130). A solução habermasiana à nova tensão entre o abstrato e o concreto criada pelo processo de globalização é a extensão parcial do concreto. Os países com tradição de democracia e cidadania podem criar um pano de fundo comum para a sua extensão pós-nacional. Ao mesmo tempo, Habermas é amplamente céptico sobre a capacidade de uma dimensão ética e política comum capaz de ancorar uma proposta como a de David Held, de uma democracia cosmopolita. Faltaria, portanto, à teoria habermasiana, a capacidade de estender o concreto da cidadania além de uma tradição cultural relativamente homogênea. Antes de partir para minha proposta em relação a essa questão gostaria de discutir uma terceira tradição de análise da globalização, aquela proposta por Boaventura de Sousa Santos.

A teoria da globalização proposta por Boaventura é mais contraditória e mais multifacetada que aquela proposta pelos dois outros autores. Em primeiro lugar, ela aceita a expansão de certos processos econômicos, políticos e culturais para o nível planetário, mas ao mesmo tempo não supõe que certas contradições próprias à primeira modernidade deixaram de operar. Boaventura propõe duas categorias para entender o que ele denomina processo de globalização hegemônica: as categorias de localismo globalizado e de globalismo localizado (Santos,1995b:263). Por localismo globalizado ele irá entender as características abstratas de certas sociedades, em particular a européia e a norte-americana, que se estendem ao longo do globo terrestre: "Aí é possível identificar uma série de características que parecem estar presentes globalmente: a prevalência do princípio do mercado sobre o princípio do Estado; a financeirização da economia mundial; a total subordinação dos interesses do trabalho aos interesses do capital; o protagonismo incondicional das empresas multinacionais..." (Santos,2001:55). Por outro lado, os localismo globalizados, isso é, os abstratos oriundos da categoria mercado que se internacionalizam, não vigoram de modo homogêneo ao longo do planeta e se combinam, tanto no campo do mercado quanto no campo do Estado, com certos concretos, que Boaventura denomina processo de localização dos globalismos, entre os quais caberia destacar: "a trajetória histórica do capitalismo nacional; a estrutura de classes; o nível de desenvolvimento tecnológico; o grau de institucionalização dos conflitos sociais". Ou seja, ele procura mostrar que 
a globalização é um processo abstrato que se encontra com processos concretos em três níveis principais, o da economia, o da política e o da cultura(que no nível internacional substitui a categoria de comunidade). Em cada nível haveria um abstrato que seria um modelo de financeirização, um modelo de internacionalização das estruturas estatais e um modelo de internacionalização da cultura. Em cada caso o abstrato seria representado pela homogeinização e pela universalidade próprios à transcendência do modo territorial de organização da economia e da política, ao passo que o concreto seria a continuidade de elementos específicos de assimilação do global pelo local. Nesse sentido, Boaventura rompe também com elementos da análise dos clássicos das ciências sociais, em particular, com elementos da tradição marxiana (Santos,1995:251). ${ }^{10}$ Para ele a questão central da globalização seria o modo específico de articulação entre o concreto e o abstrato nas campos da economia e do Estado que produziriam a tensão entre globalização hegemônica e a globalização contra-hegemônica.

Para analisar ao globalização contra-hegemônica Boaventura lança mão de duas categorias adicionais, as categorias de cosmopolitismo e de herança comum da humanidade. Por cosmopolitismo ele entende a atividade dos grupos subordinados no interior da globalização "estadosnação, regiões, classes ou grupos sociais e seus aliados de organizar-se transnacionalmente em defesa de interesses comuns e utilizar, para o seu próprio benefício, as potencialidades de interação transnacional criadas pelo sistema mundial. Tal organização tem a intenção de contrarrestar efeitos perversos das formas hegemônicas de globalização e surge da percepção de novas oportunidades para a criatividade e a solidariedade internacional criadas pela intensificação da interação global"(Santos, 1995:263). A análise de Boaventura tem diversos elementos cuja decomposição analítica pode nos ajudar a entender melhor a sua análise do processo de globalização. Por um lado, parte da negação do suposto marxinano da homogeineização universal. Para ele cada abstrato produzido pelas categorias mercado e Estado se encontra com um concreto específico, que ele denomina globalismo localizado. Por outro lado, aproximandose da análise marxiana, Boaventura vai supor que a aceleração dos processos globais provocados pelo aumento da movimentação de mercadorias e pessoas cria um potencial interativo internacionalizado comum expresso

10 A questão central da revisão de Marx por Boaventura é o nível de homegeinização global suposto por Max nos seus escritos sobre a expansão do capitalismo, em particular no Manifesto Comunista. 
nas mais de sete milhões de pessoas que cruzam fronteiras no mundo todos os dias. É esse processo interativo comum, gerado por interações concretas, que Boaventura identifica com o cosmopolitismo que se expressa nas diferentes rearticulações de atores sociais para redefinir o processo de globalização. O fundamental, no entanto, é como cada uma dessas categorias se expressa no direito: a globalização hegemônica se expressa como lex mercadoria ao passo que a contra-globalização não hegemônica se expressa na herança comum ou no assim chamado jus humanitatis. Esse último é definido como "a expressão da aspiração a uma forma de governança dos recursos naturais e culturais que... devem ser considerados como possuídos globalmente e geridos no interesse da humanidade como um todo tanto no presente quanto no futuro" (Santos,1995:365).

É possível, portanto, perceber que a relação entre abstrato e concreto encontra em Boaventura duas formulações complementares: em uma primeira, os processo específicos de globalização envolvem, como foi mostrado acima, uma relação entre abstrato e concreto no interior da qual as relação Norte-Sul e as relações Sul-Sul são inseridas. Em uma segunda formulação, a questão da cidadania, especialmente no que tange ao problema dos direitos humanos, é recuperada a partir de um eixo de contra-globalização expresso pelas categorias de cosmopolitismo e herança comum, categorias essas que ligam o problema da cidadania e da emancipação a uma dimensão abstrata formada pela generalidade e pela universalidade das formas de interação criadas pelo próprio processo de globalização. Desse modo, Boaventura expressa uma terceira forma de entender a relação entre o abstrato e o concreto na globalização, que é romper com a dicotomia proposta pelos clássicos das ciências sociais e perceber elementos emancipatórios tanto no concreto quanto no abstrato. $\mathrm{O}$ direito seria a categoria capaz de expressar essa disputa, embora na forma como o conflito entre lex mercadoria e jus humanitatis aparece descrito fique difícil conceber o direito como um concreto capaz de expressar a contra-globalização nas seis dimensões apontadas acima. Falta, portanto, um elemento concreto de cidadania capaz de constituir o concreto nos eixos do cosmopolitismo e da herança comum.

\section{O CONCRETO, O ABSTRATO E A CIDADANIA MUNDIAL}

Como é possível perceber, todos os três autores discutidos acima tem problemas em identificar categorias concretas de cidadania na globa- 
lização e cada um deles propõe uma solução distinta para o problema: Giddens abole a categoria de concreto na globalização e transfere todos os potenciais de cidadania para o campo da abstração; Habermas percebe a nova relação entre abstrato e concreto mas consegue apenas apontar uma nova base concreta européia para a extensão da cidadania e Boaventura transfere o concreto para os processo de localização da globalização mas, ao pensar as formas de contra-globalização, só consegue baseá-las em um categorias generalizante próprias ao abstrato. O problema, portanto, que nos resta abordar nesse trabalho é: como conceber a relação entre o abstrato e o concreto para pensar uma categoria de cidadania mundial.

A meu ver é necessário em primeiro lugar romper, da forma como fizeram Giddens e Boaventura, com a idéia dos clássicos das ciências sociais - Marx, em particular - de que a cidadania só se localiza no campo do concreto. É evidente que apesar de Giddens ter uma intuição a esse respeito a sua solução para o problema joga fora a criança junto com a água do banho: ao se livrar do concreto para ressaltar o abstrato, Giddens perde qualquer capacidade de pensar a cidadania no mundo globalizado como resultado da ação coletiva. A esse respeito Boaventura parece ter a solução mais consistente: a de relativizar o processo de relação entre o concreto e o abstrato admitindo que a modernidade é uma modernidade múltipla e policêntrica. Consegue assim mostrar que existem diversas formas de abstração - as ligadas à expansão do mercado mundial, as ligadas à internacionalização do Estado e aquelas ligadas a homogeinização cultural - e que cada uma das formas de abstração produz um concreto específico, que é o "globalismo localizado". A solução de Boaventura para o problema da abstração me parece mais consistente do que as soluções apresentadas por Giddens - que unicamente faz uma apologia da globalização - e Habermas, o autor que continua conectando abstração com dominação. Essa posição, derivada tanto da obra de Marx quanto da obra de Weber, enfrenta um problema resultante de uma mudança de perspectiva derivada da própria globalização: na medida em que os indivíduos se movimentam para fora do Estado nacional, em processos muitas vezes desvinculados da cidadania nacional - casos, por exemplo, da migração forçada ou dos trabalhadores ilegais - eles precisam de uma proteção cidadã, que deve assumir elementos transnacionais e, portanto, abstratos. Não é possível, portanto, pensar nas categorias da cidadania na globalização apenas como concretos. Elas devem envolver elementos de abstração da própria condição da cidadania em relação ao Estado nacional.

Seria possível pensar no mundo em globalização em duas cate- 
gorias de cidadania abstrata: a primeira delas é uma cidadania legal transnacional, capaz de dar direitos civis perante os tribunais às pessoas que estão provisoriamente ou permanentemente sem cidadania. A segunda categoria seria de uma cidadania social transnacional, capaz de assegurar no plano internacional direitos sociais e especialmente condições mínimas de trabalho para que as mercadorias possam circular internacionalmente. Em cada um desses casos, trata-se claramente de uma categoria de abstração capaz de contrarrestar um processo de expansão do mercado e do Estado ao nível global. No caso dos direitos legais, trata-se de criar uma base legal para a circulação dos indivíduos em um mundo no qual apenas a circulação de mercadorias tem base legal e de obrigar o sistema dos estados nacionais a estender o processo de internacionalização das mercadorias para as pessoas. No caso dos direitos sociais globais trata-se de coibir, no processo de extensão do mercado, a re-mercantilização do trabalho, obrigando o mercado a aceitar um nível internacional de regulamentação das condições de trabalho para que as mercadorias possam circular. Ambas as propostas já se assentam em propostas feitas por movimentos sociais de espectro global, tais como o movimento anti-sweatshops e o movimento pelos direitos dos imigrantes ilegais (Soysal,1994). Persiste, no entanto, para se entender o problema da cidadania global entender a forma como devemos pensar os concretos.

Entre os três atores tratados acima apenas dois problematizam a questão do concreto, Habermas e Boaventura. Para Habermas a questão do concreto assume uma conotação bastante clara: trata-se de pensar aquelas condições que irão permitir o florecimento de um mundo da vida transnacional capaz de se constituir em pano de fundo político-cultural para o processo de democratização da expansão dos mercados e dos estados para o nível transnacional. A abordagem habermasiana tem um ponto forte e um ponto fraco: o ponto forte é de procurar estabelecer a base cultural do processo de criação de um mundo da vida transnacional nas próprias dimensões do concreto, isso é, nas práticas dos indivíduos, dos atores sociais e das formas de ação coletiva disponíveis no plano transnacional. Por outro lado, Habermas possui um ceticismo em relação à extensão desse marco para além da velha Europa, mostrando que na verdade a modernidade para ele continua sendo um processo de europeização do mundo não-europeu (Said, 1978). Esse é o motivo pelo qual ele trabalha apenas com uma dimensão do concreto. Mais uma vez, Boaventura possui uma solução mais consistente. Ele designa seis tipos de concreto - o espaço doméstico, o da produção, do mercado, o da comunidade, o da cidadania e 
o espaço mundial - como locales nos quais se manifestam as diferentes formas de poder. O problema é que esses locales para se constituírem em concretos geradores de cidadania precisam se articular com as formas específicas de um abstrato capaz de gerar cidadania. Isso, a meu ver, implica pensar uma articulação entre as categorias abstratas de uma cidadania desterritorializada e as categorias concretas deduzidas de formas de poder específicas. Esse é o trabalho que a meu ver restaria ser feito para a emergência de uma teoria da cidadania na globalização.

Pelo menos em dois campos é possível apontar como se daria uma articulação entre o abstrato e o concreto no nível global: no campo de um cidadania legal desterritorializada e no campo de uma cidadania global social mínima. Em cada um desses campos, tal como foi mostrado acima, existiria um elemento abstrato de cidadania pós-nacional. No campo civil e legal essa cidadania se expressaria pelo fato de os direitos legais já terem uma base normativa transnacional expressa no fato de os estados nacionais reconhecerem, no caso dos direitos humanos e dos direitos civis, a sua aplicação aos não cidadãos no interior do Estado nacional. ${ }^{11}$ Desse modo, o elemento pósnacional passa a estar ligado a uma dimensão normativa já presente na era dos estados nacionais mas irá, apenas agora, adquirir uma formulação legal pós-nacional (Vincent,1992). É essa dimensão que identificamos com uma cidadania abstrata em nível internacional.

Ao mesmo tempo, os problemas concretos de extensão da cidadania legal para aqueles que mais intensamente se movimentam fora dos limites dos seus estados nacionais exige um concreto, representado ou por movimentos de direitos humanos ou por lutas de extensão da cidadania no interior dos estados nos quais os não cidadãos se encontram. O mesmo é possível de ser afirmado no caso de direitos sociais mínimos. Por um lado, ainda que a normatividade em relação aos direitos sociais seja menos difundida do que a normatividade em relação aos direitos civis, ela pode apoiar-se seja em uma base histórica - as lutas passadas contra a escravidão - ou em uma base nacional em expansão a solidariedade dos trabalhadores do primeiro mundo em relação àque-

11 Jean Cohen aponta corretamente que, para tal, faz-se necessário a superação da idéia moderna de cidadania calcada na exclusividade do demos e sua substituição por um status de indivíduo com direitos legal para todas as pessoas que estejam no interior de um dado Estado nacional. Ao adotar tal solução ela percebe que a exclusividade do demos como articulador da cidadania - a formulação mais comum na era dos estados nacionais - deve dar lugar a múltiplos conceitos de cidadania, alguns fortes e alguns fracos, que não devem coincidir com os limites territoriais dos estados nacionais. (Vide Cohen,1999). 
les que são super-explorados no mundo em desenvolvimento. Em ambos os casos, a idéia abstrata de uma cidadania social transnacional se conecta com elementos de luta concreta que podem se manifestar tanto internacionalmente quanto no interior de estados nacionais específicos. Mais uma vez, é possível perceber como o abstrato de uma cidadania social pós-nacional pode se articular com o concreto de lutas contra a super-exploração, limitando um outro abstrato, no caso o mercado mundial não regulado de mercadorias. Em ambos os casos é interessante notar que o concreto assume a forma de uma movimentos social transnacional que se desdobra em lutas locais. Em ambos os casos é importante perceber também que o concreto habermasiano de um mundo da vida pós-nacional se articula com lutas específicas fora dos centros europeus e norte-americanos da modernidade, criando perspectivas normativas comuns além desses locais.

Podemos assim concluir o nosso itinerário no interior da teoria social fazendo a seguinte constatação. Por um lado é possível e necessário avançar além de Marx e Weber na questão da elaboração de categorias abstratas capazes de potencializar uma ampliação da cidadania ao nível global. Por outro lado, tentativas como as de Giddens de abandonar as categorias do concreto levam à adesão acrítica a um processo de globalização que solapa dimensões importantes da cidadania. A questão para a teoria social do século XXI é como associar o abstrato de categorias de uma cidadania pós-nacional como lutas concretas pela limitação das formas de expansão do mercado e, em alguns casos, do Estado para além da territorialidade nacional. Essa lutas tem se concentrado nos campos do civil e do social pela própria natureza da globalização baseada em grande parte no fluxo de indivíduos e mercadorias. São nessas áreas que tem surgido movimentos sociais pós-nacionais que tem tocado fundamentalmente nas questões civil e social. Isso não quer dizer que o elemento político da cidadania não se vá colocar no ordem do dia em algum momento e vir a constituir um novo concreto de lutas democráticas. É da ação dos atores sociais nesse campo que dependerá a extensão da cidadania mundial para o campo do político. 


\section{REFERÊNCIAS BIBLIOGRÁFICAS}

AVRITZER, L. (1996). A Moralidade da Democracia. São Paulo, Perspectiva.

AVRITZER, L. (2000). "Entre o diálogo e a reflexividade: a modernidade tardia e a mídia". in L. Avritzer e J. M. Domingues (org.) Teoria social e modernidade no Brasil. Belo Horizonte, Editora UFMG.

COHEN, Jean. (1999)."Changing Paradigms of Citizenship and the Exclusiveness of the Demos". International Sociology. vol 14, n. 3.

COSTA, Sérgio.(2001). "Teoria social, cosmopolitismo e a constelação pós-nacional". Novos Estudos, n. 59.

DOMINGUES, J. M. (2000). "Desencaixe, abstrações e identidades". in L. Avritzer and J. M. Domingues (org.) Teoria social e modernidade no Brasil. Belo Horizonte, Editora UFMG.

GIDDENS, A. (1981). A Contemporary Critique of Historical Materialism. Berkeley, University of California Press.

GIDDENS, A. (1984). The Constitution of Society : Introduction to the Theory of Structuration. Berkeley, University of California Press.

GIDDENS, A. (1990). The Consequences of Modernity. Stanford, Stanford University Press.

GIDDENS, A. (1991). Modernity and Self-identity : Self and Society in the Late Modern Age. Stanford, Stanford University Press.

GIDDENS, A. (1994). Beyond Left and Right : the Future of Radical Politics. Stanford, Stanford University Press.

HABERMAS, J. (1984). The Theory of Communicative Action. Boston, Beacon Press.

HABERMAS, J. (1995). Between Facts and Norms. Cambridge, MIT Press.

HABERMAS, J. (2000). La Constelacion Postnacional. Buenos Aires, Paidos.

HISRT, P. and Thompson (1995). Globalization in Question. Cambridge, Polity Press.

MARX, K. (1975). Early Writings. New York, Vintage Books.

SANTOS, Boaventura de Sousa. (1995). Toward a New Common Sense. London, Routledge.

SANTOS, Boaventura de Sousa. (2000). Crítica da razão indolente. São Paulo, Cortez.

SANTOS, Boaventura de Souza. (2001). Globalização:fatalidade ou utopia. Porto:Edições Afrontamento.

SOYSAL, Y. (1994). Limits of Citizenship. Chicago, University of Chicago Press.

THOMPSON, J. (1995). The Media and Modernity. London, Polity Press.

WEBER, M., H. H. Gerth, et al. (1946). From Max Weber: Essays in Sociology. New York, Oxford University Press.

WEBER, Max. 1978. Economy and Society. Berkeley:University of California Press. 